\title{
INCLUSIVE CLASSROOM - TEACHING MULTICULTURAL GROUPS OF STUDENTS - AN INTERCULTURAL PROJECT WITH STUDENTS FROM 13 COUNTRIES
}

\author{
LUCYNA WILINKIEWICZ-GÓRNIAK
}

\begin{abstract}
"An increasingly international, interdependent, and diverse world rewards people with global competencies and understanding, such as the ability to make local-to-global connections, recognize divergent perspectives, think critically and creatively about global challenges, and collaborate respectfully in heterogeneous forums. [...] "Global citizenship is an element of citizenship readiness that requires a global skill set, including social and cross-cultural skills, proficiency in languages other than English, and an understanding of economic and political forces that affect society."
\end{abstract}

(Partnership for 21st Century Learning, 2014, p. 4)

\begin{abstract}
Educating multicultural groups is not easy as a teacher has to deal with students from different cultural backgrounds in limited space and time. Still, it is feasible, provided that we are able to create a positive and trusting classroom environment in which all students are made to feel valued, respected and welcome. The one that combats stereotypes and prejudices allows multiple perspectives and ways of thinking and helps students develop a positive self-image. In such a classroom students can develop not only knowledge and skills, but also multicultural awareness, if only they are willing to coexist and cooperate with each other as well as accept and appreciate their varied backgrounds. Some points that I found to be the keys to success in my applied research are: culturally responsive teaching and differentiated instruction taking into account not only cultural diversity but also different learning styles and preferences. Apart from their flexibility in the area of methodology, a teacher should use a multisensory approach to appeal to different learning styles.
\end{abstract}

Key words: universal human experience across cultures, creating collaborative teams 


\section{Introduction}

The article below concerns the author's observations and conclusions drawn from the experience of teaching a group of students coming from 13 countries, both native and non-native speakers of English at varying levels of advancement.

While reporting on this experience the author starts with the general description of the whole project and its assumed results and then, after reflecting on the initial challenge of multicultural education, moves on towards describing some solutions, the so-called: building blocks of positive classroom.

Among these there are such elements as: clear specification of rules and requirements at the beginning of the course, participatory approach and role-reversal, treating problems as challenges, positive community creation, teacher's availability, inclusion and tolerance, sharing, respect towards each other, honesty and, last but not least, coexistence of various "Englishes" - International English and native speakers' English. Thanks to the process of ongoing (continuous) communication the goals of the whole project are achievable.

\section{Description of the project}

The intercultural project described below was an elective course and it covered one semester of "Effective organizational communication" consisting of 60 hours of: lectures (30 hours) and classes (30 hours) in English, divided between 15 weeks, which meant 4 hours each week; 2 hours of lectures and 2 hours of classes. The project method was used during both, facilitating active participation of the students, and, on the teacher's part, constant planning and re-planning - in order to obtain the final goal: successful knowledge implementation into two projects - signature and exam project. The required level of English: C1 (CEFR)

The following areas were included in the course:

1. Lectures:

- Theoretical issues related to effective organizational communication

- The recruitment and selection process of an organization

- Introduction to project management

2. Classes:

Professional portfolio

Based on the background information presented by the teacher the students were expected to prepare an individual project during the classes, considered to be the "signature project", entitled "Career portfolio" and an "exam project" - team or individual (if there was only one person from a given country) "My country and Poland, cultural similarities and differences" (as shown below). 


\begin{tabular}{|c|}
\hline $\begin{array}{c}\text { Our intercultural project }-1 \text { semester } \\
\text { Time frame, activities, tasks }\end{array}$ \\
\hline $\begin{array}{c}\text { Total: } 60 \text { hours } 30 \text { hours of lectures plus } 30 \text { hours of classes } \\
\text { Each week: } 2 \text { hours of classes plus } 2 \text { hours of lectures }\end{array}$ \\
\hline Classes: individual ,signature project” \\
"Career Portfolio" \\
\hline Lectures: team / individual „exam project” \\
„My country and Poland, cultural similarities and differences” \\
\hline
\end{tabular}

Both of these tasks assessed students' ability to implement knowledge acquired during the course - about effective organizational communication and recruitment as well as their capability of managing individual and team projects.

The participants were 55 students from 13 countries (for the exact number of students from each country see the table below) with Polish students making up the biggest group: 20 persons. All 55 students participated in the lectures together and for the classes they were divided into two groups of 28 (group A) and 27 (group B) students.

\begin{tabular}{|c|c|c|c|}
\hline \multicolumn{4}{|c|}{ Our intercultural project -13 countries [number of students] } \\
\hline Erasmus students from 12 counties and Polish students \\
\hline Great Britain & USA & South Korea & Japan \\
{$[2]$} & {$[2]$} & {$[3]$} & Mexico \\
\hline Germany & France & Spain & {$[1]$} \\
{$[4]$} & {$[9]$} & {$[3]$} & Egipt \\
\hline Uzbekistan $[1]$ & Ukraine & Croatia & {$[1]$} \\
\hline \multicolumn{3}{|c|}{ Poland $-[20]-$ Hosting country } \\
\hline \multicolumn{3}{|c|}{ TOTAL: $35+20=55$ students } \\
\hline
\end{tabular}

Since all Polish students had already completed three out of four semesters of "Business communication - basic course" they were considered to be "experts" in the area of effective organizational communication, and therefore it was theirs, rather than teacher's responsibility to present during the "lectures" part various areas of organizational communication to their colleagues from other countries (as shown below). The topics from the handbook (Blundel, Ippolito and Donnarumma, 2013) used during the course can be seen on the right side of the table below; they made up the basic framework for the classes, which was further advanced by adding the teacher's own ideas, presented on the left side of the aforementioned table. 


\begin{tabular}{|l|l|}
\hline \multicolumn{1}{|c|}{ A Course in Business Communication } & \multicolumn{1}{|c|}{ Effective Organisational Communication } \\
\hline The role of business communication: & \\
The process of human communication: & Perspectives on communication \\
Written forms of business communication: letters $/$ & Breaking barriers: communication in practice \\
brief messages / reports & Using words: verbal communication \\
Oral communication in business: informal talking, & Making pictures: non-verbal communication \\
listening, interviews, presentations (individual & Developing arguments: persuasive communication \\
and team-collaborative), meetings, negotiations, & Establishing a dialogue: interactive communica- \\
speeches, oral reporting & tion \\
Non-verbal communication & Making connections: organisational communication \\
Intercultural communication: tips for communi- \\
cating with people from other cultures
\end{tabular}

The teacher, in turn, presented the recruitment and selection process of an organization to the whole group (during the lectures), together with the basic elements and ways of drawing up a professional portfolio (during the classes) and the necessary information concerning project management (also shared in the lectures), providing them with a set of templates for their two projects.


Team project's presentation templates - "The four slides"

Above I present the first "four slides" templates in the set of all templates for the final presentation of team projects, which were provided by the teacher. The students were expected to prepare and present "Four slides" at least two weeks in advance of the final project's presentation. During these brief "Four slides" presentations course participants were able to clarify any problems related to their project work, see what their slides look like while projected on the wall (colors, spacing, contrast, imagery, etc.) and, possibly, still improve their "final product" before the end of the project.

As there were more than fifty participants of the course and each of them had to present two projects, introductory lectures and classes covered approximately half of the time, i.e. 30 hours out of 60 . In the remaining 30 hours students were expected to present their two "products" and then each of them received detailed feedback from the teacher concerning their skills and abilities worth developing and areas of improvement. If the final grades were not satisfactory for any of the students, they 
were given their "second chance" to improve these grades during office hours, and some students were really happy to use this opportunity. We called it the policy of "leaving the door ajar".

Follow-up remarks:

As a result, all students managed to complete their projects on time. Most of them received either very good or good grades. In a few cases they chose to repeat final presentations, using the guidelines from the teacher how to make them better.

\section{Final products}

The first final product, the so-called "Signature project" - professional portfolio, was composed of nine elements which were to be prepared and presented by each student individually. These were:

- Task 1: My personal profile

- Task 2: My present job

- Task 3: The job of my dreams

- Task 4: Job advert for me - the one that I have managed to find / description of such an advert if I have not managed to find it

- Task 5: Un/solicited letter of application

- Task 6: CV

- Task 7: Portfolio - list of certificates, etc.

- Task 8: Job interview - this task was completed in pairs or groups of three students

- Task 9: My USPs (skills, abilities)

The time limit for each of these tasks was: 3-5 minutes per person.

The second final product, the so-called "Exam project" - team or individual was a presentation of the culture of the country each participant represented and its comparison/contrast to Polish culture. Altogether students prepared 18 projects. However, because the "Polish team" consisted of 20 students, only one part of them presented Polish culture (6 students), while others chose to present some useful topics related to intercultural communication.

The list of final projects:

Final project 1 - "Croatia and Poland - cultural similarities and differences" [2 team members]

Final project 2 - "Essential cultural differences in business" [4 team members, Polish students]

Final project 3 - "Mexican project" [individual presentation]

Final project 4 - "Ukrainian Project" - team presentation [6 team members]

Final project 5 - "Polish Project" - team presentation [6 team members] 
Final project 6 - "South Korean Project" - team presentation [3 team members]

Final project 7: "Egyptian Project" - "Egypt as a unique Middle Eastern country"

[individual presentation]

Final project 8: "Japanese Project" - individual presentation

Final project 9: "French Project" - team presentation [the biggest team, composed of

9 members]

Final project 10: "American Project" - "USA" - team presentation [2 team members]

Final project 11: Uzbek Project" [individual presentation]

Final project 12: "Stereotypes" - team presentation [4 team members, Polish students]

Final project 13: "The most famous people from Poland" - [individual presentation, Polish student]

Final project 14: "British Project" - United Kingdom" - team presentation [2 team members]

Final project 15: "Saleswomen" - team presentation [4 team members, Polish students]

Final project 16: "German Project" - team presentation [4 team members]

Final project 17: "Spanish Project" - team presentation [3 team members]

Final project 18: "Silesian Project" - "Silesian autonomy and uniqueness" - [individual presentation, Polish student]

As can be seen from the list, apart from the presentations of 13 different countries, students also concentrated on cultural differences in business (project 2), the role of stereotypes in intercultural communication (project 12), the most famous people in Poland and their role in intercultural communication (project 13). They also presented an example of regional culture in the project concerning Silesian autonomy and uniqueness, and their own students' group culture - in a mysteriously-sounding project entitled "Saleswomen", as they pretended to sell their own group while presenting its characteristics.

\section{The teacher's observations and reflections concerning the characteristics and methods of work in a multicultural classroom}

\section{Initial challenge}

"Generally speaking, multicultural education is predicated on the principle of educational equity for all students, regardless of culture, and it strives to remove barriers to educational opportunities and success for students from different cultural backgrounds." (Great Schools Partnership, )

Dealing with students from different cultural backgrounds, a teacher must be able to understand and accept variety. This refers to the whole range of issues, such as: different notions of time, punctuality, varying approaches to learning, both: in the classroom and outside it (e.g. attitude to homework), or students' willingness to 
participate in the activities offered by their teacher, and many others. This is a formidable task, especially that the process of communication may turn out to be difficult due to variety of accents, level of English, vocabulary range, ways of communicating - both: verbally (scarcity versus abundance of words), and non-verbally (scarcity versus abundance of gestures).

A multicultural classroom is a big challenge and it means extra work for a teacher, but it may also turn out to be really rewarding, giving both students and the teacher a unique feeling of success. In such a classroom differences existing between students coming from various cultures should be used by the teacher as "building blocks" in course construction. In order to discover students' human potential a teacher can use an introductory brainstorming session entitled "What are you good at?" Such a session will not only make it possible for the students and the teacher to get to know each other, but, more importantly, it will create a positive atmosphere in the classroom by showing each student their intellectual potential. Such an atmosphere is of key importance, especially in a multicultural classroom.

As specified on the webpage of Partnership for 21st Century Learning, globalready teachers must not only have knowledge about multicultural context and skills enabling them to make learning effective. The key to their success is proper attitude towards their students during the whole process of teaching-learning taking place in a global classroom. (Partnership for 21st Century Skills, p. 44)

\section{Solution: building blocks of positive classroom}

"Essential for developing multicultural/diverse perspective learnings is a positive and trusting classroom environment - one in which all students are made to feel welcome, comfortable, and respected." (Pikulski \& Cooper, 1997)

Among the building blocks of a positive classroom there are such elements as:

\section{Clear specification of rules and requirements at the beginning of the course}

This rule, which is one of the key requirements of every course, in the case of multicultural groups of students is especially important. Each student joining the group must be given a chance to understand what the course offers and what outcomes are expected of them. Imagining the structure of the group a teacher should be able to formulate the goals and content of the course in such a way that it corresponds with students' background knowledge and skills and it takes into consideration their expectations.

Thus specified "code of practice" should be adhered to throughout the whole course. However, this process of teaching-learning should be monitored by the teacher since the very beginning, and, if necessary, a teacher has to be ready to modify its segments, also those concerning the requirements, in the continuous process of planning and re-planning. 


\section{Participatory approach}

Participatory approach towards the teaching-learning process is especially welcome in this type of classroom. Students should be encouraged to ask questions and thus make it possible for a teacher to adapt the syllabus to their needs and clarify all misunderstandings without delay. In the case of "Intercultural Project" described here one of the biggest challenges was the fact that some students had broad knowledge of organizational communication (Polish students - who had already completed the so-called: "basic course"), while others (Erasmus students) had to learn the basics to be able to compete with their peers. The solution chosen by the teacher was to have this section of theoretical knowledge presented by Polish students. The teacher played the role of an external advisor, ready to supplement the necessary knowledge or explain some of more difficult issues to Erasmus students.

\section{Role-reversal}

Since each participant of "Intercultural project" was an expert in the area of their own culture and its characteristics, in this part of the course a teacher was also a learner, and, as such, was allowed to ask questions concerning situations which were new or unexpected to them. This is what Banks used to call "equity pedagogy" while writing about multicultural education:

"The teacher and the students share. They learn together and share their perspectives. They become joint learners in this multicultural classroom. The teacher has a culture, and the teacher and students learn together, share their cultures and construct new knowledge in the classroom. That's how I see teachers reconceptualizing their role." (Banks, p. 4)

\section{Treating problems as challenges and opportunities to learn more}

Problems should be treated by a teacher as challenges and they ought to be solved promptly. A teacher should never let them "grow", as this would definitely increase the distance between them and the students, and thus it might spoil the positive atmosphere inadvertently, making students unwilling to cooperate with the teacher and with each other.

\section{Teacher's availability}

In the case of multicultural groups it is especially important to be available to our students - during regularly conducted office hours, through email correspondence, by sparing 5-10 minutes at the end of each lesson/lecture for students if problems appear.

\section{Positive community creation, inclusion and tolerance, networking to share}

Bearing in mind that students may not know each other, a teacher should encourage them to network and cooperate with each other, e.g. by giving them tasks 
which require collaboration and providing them with guidelines concerning their completion as well as expressing willingness to help if problems appear.

"Inclusive teaching strategies refer to any number of teaching approaches that address the needs of students with a variety of backgrounds, learning styles, and abilities. These strategies contribute to an overall inclusive learning environment, in which students feel equally valued." (Centre for Teaching Innovation, Cornell University)

\section{Dignity and respect}

Differences between students should be taken for granted and each student should be treated as a UNIQUE human being. Instead of judging their peers, students should be encouraged by the teacher to search for the reasons of differences among them in order to understand them better.

\section{Uniqueness rather than oddity}

It is the teacher's task to help students discover their unique features and offer them opportunities (tasks, activities) to work on reinforcing and developing these. Therefore in the final task of the so-called "signature project": task 9: concerning "my USPs - skills, abilities" students were expected to specify what makes them different and unique, in order to be able to use this knowledge both in the classroom and in their future professional career.

\section{Honesty and diplomacy}

Being honest with the students is the best strategy to solve problems with difficult names, different attitudes to punctuality, absences, deadlines, etc. A teacher should avoid judging students who are, for example, late to a lecture, as it was the case of Spanish students participating in the course analysed. Instead, they ought to try to understand their behaviour and explain various notions of time and punctuality to other students who might have a tendency to be extremely critical towards the "latecomers", as it was the case of German students participating in the course who were always very punctual.

A teacher should make the rules clear to their students. They should be aware not only of what they are expected to do, but also what types of behaviour are acceptable or not. If they misbehave, a teacher should make it clear to them in a tactful way. Likewise, the clarification of problems and/or misunderstandings presented by the students to the teacher should be carried out in a positive, diplomatic manner (in fact, this is a very good opportunity for a teacher to help students develop positive persuasion and negotiation skills)

If something goes wrong and a student's performance is below the teacher's expectations, a teacher should present their evaluation in an honest but, at the same time also: diplomatic way. Instead of being overly critical, a teacher should encour- 
age their students to use their "second chance". This "yes, you can" approach, with positive reinforcement and encouragement to continue working is the best motivator and stimulator on the path toward success. The results students achieve while being positively motivated very often surpass a teacher's expectations.

10. Coexistence of various "Englishes" - International English and native speakers' English/es

International English is far from being perfect, so a teacher must listen to their students very attentively and be ready to help - in order to make sure that students understand each other while communicating in the classroom. Visual communication and infographics are especially useful in a multicultural group of students, especially, that both: the level of advancement and vocabulary range differ significantly in such a group of students.

Another problem may be caused by native speakers who usually speak too fast to be understood by non-native users of English. What's more, the range of vocabulary used by native speakers, with the whole variety of idioms and dialects may be too much of a challenge for non-natives.

As Chia Suan Chong proves, there is the whole range of reasons why native speakers are unable to communicate well in international setting, such as: not understanding the nature of communicating in a second language and thus being less tolerant of mistakes or foreign accents which they do not understand easily. With their clear-cut distinction between "high level English" and low-level English", native speakers tend to be intolerant towards lower level users of English, especially that they themselves are not familiar with the complicated process of a foreign language acquisition. (Chong, 2016)

That is why a teacher has a very important role to play in a multicultural classroom. They ought to pay attention to the process of communication taking place among students and intervene if needed. In this sense they should not only be a facilitator in the process of communication, but also a clarifier, pacifier and a diplomat in order to eliminate tensions among students communicating on a daily basis.

To make this process effective, a teacher should encourage students to honestly admit that they have some problem with understanding their colleagues. Contrary to what one might think, it is not an easy task and it can only be accomplished if students feel positive atmosphere in the classroom, in which they are safe because they are accepted by other students and a teacher who is an attentive participant of the whole communication process.

As Aya Matsuda specifies it: "The understanding of World Englishes does not consist of a set of discrete items or topics that can be tucked in at the beginning of the semester, between formal chapters, or during the first 5 minutes of every lesson and then be forgotten. It is, rather, a different way of looking at the language, which 
is more inclusive, pluralistic, and accepting than the traditional, monolithic view of English in which there is one correct, standard way of using English that all speakers must strive for.“ (Matsuda, 2003: 726-727)

\section{Ongoing (continuous) communication}

As it has already been stressed in the previous section, the process of communication among students as well as a teacher and their students should never stop. The importance of this ongoing communication in a multicultural classroom cannot be underestimated.

\section{Conclusions}

As it can be seen from the above analysis, a multicultural classroom is a challenging environment, even for an experienced teacher. In such an educational setting the key to success is ongoing positive communication with the students.

It should start by analysing the initial situation in order to specify the profiles, needs and expectations of the students and juxtapose them with the components of the course offered. Based on this, a teacher should be able to determine the framework of the course, in terms of content, requirements and forms of participation.

Having constructed this framework a teacher should communicate it to the students in a clear and understandable way, encouraging them at the same time to ask questions whenever they have some comprehension problems.

As the course develops and students prepare their tasks, a teacher ought to be available and willing to help them solve any problems that may occur. These may not only be problems concerning task-preparation and completion but also those related to communication with other students. It is the teacher's role to create positive community of students who, being aware of cultural and personality differences, are also tolerant towards them and willing to achieve positive results together.

At the end of a course, apart from being graded, students should also be provided with constructive feedback which will make it possible for them to build on their strengths while at the same time trying to work on the elimination of weaknesses.

„Essential for developing multicultural/diverse perspective learnings is a positive and trusting classroom environment - one in which all students are made to feel welcome, comfortable, and respected." (Pikulski and Cooper, 1997)

\section{Bibliography}

Banks, J. A. Multiculturalism's five dimensions. Retrieved 25.02.2018, https://www.learner.org/work shops/socialstudies/pdf/session3/3.Multiculturalism.pdf. 
Blundel, R., Ippolito, K. and D. Donnarumma. 2013. Effective organisational communication: perspectives, principles and practices. (4 ed.). Harlow: Pearson.

Centre for Teaching Innovation, Cornell University. „Inclusive teaching strategies”. Retrieved 25.02.2018.

Chong, C.S. 2016. 5 „Reasons why native speakers need to learn to speak English internationally”. English Teaching Professional. Retrieved 25.02.2018.

Great Schools Partnership. „The glossary of education reform”. Retrieved 25.02.2018, https://www. edglossary.org/multicultural-education/.

Matsuda, A. 2003. „Incorporating world Englishes in teaching English as an international language”. TESOL Quarterly. Retrieved 25.02.2018, https://www.researchgate.net/profile/Aya_Matsuda/publica tion/264577085_Incorporating_World_Englishes_in_Teaching_English_as_an_International_Langua ge/links/55e9cf5308ae21d099c391b6.pdf.

Partnership for 21 st Century Learning. (2014). „Framework for state action on global education”. Retrieved 25.02.2018, http://www.p21.org/storage/documents/Global_Education/P21_State_Framework_ on_Global_Education_New_Logo.pdf.

Partnership for 21 st Century Skills. „Teacher guide: K-12 global competence grade-level indicators”. Retrieved 25.02.2018, http://www.p21.org/storage/documents/Global_Education/P21_K-12_Global_ Ed Indicators.pdf.

Pikulski, J.J. and J.D. Cooper. 1997. „Issues in literacy development: strategies to support multicultural Instruction". Retrieved 25.02.2018, https://www.eduplace.com/rdg/res/literacy/multi2.html. 